\title{
El Trabajo Social interrogado por las epistemologías feministas. Cronotopías culturales y movimientos en torno al saber y al poder en la teoría social y en el trabajo social contemporáneo.
}

Ruth Sosa

Doctora en Humanidades y Artes (UNR)

Posdoctorado (CEA-UNC)

Master en Sociología (UNICAMP-Brasil)

Licenciada en Trabajo Social (UNR)

Docente-investigadora (UNR)

Correo: ruthsosaunr@gmail.com 
Resumen

El propósito de este artículo es recuperar algunas claves críticas del feminismo a los fines de contribuir -en ulteriores indagaciones mediante narrativas- para una problematización de los modos pedagógicos y de investigación en teoría social, así como también para la interpelación de las formas de intervención del trabajo en el campo de lo social. Se asume la capacidad heurística del prisma feminista. Se destaca la relevancia de los conocimientos situados y las cronotopías culturales como categorías socio-semióticas de investigación. Se sugieren líneas e interrogantes sobre cómo estas dimensiones han de ser agenciadas por el trabajo social.

Palabras claves:

feminismo, epistemología, cronotopías culturales, intervención

\section{Abstract}

The purpose of this article is to recover some critical keys of feminism in order to contribute, in further investigations through narratives, to the problematization of pedagogical methods and research habits in social theory, as well as the interpellation of the forms of intervention of work in the social field. The heuristic capacity of the feminist prism is presumed. The relevance of situated knowledge and cultural chronotopies are highlighted as socio-semiotic categories of research. Lines and questions regading how these dimensions have to be organized by social work are suggested.

Keywords: feminism, epistemology, cultural chronotopies, intervention 
Dedico especialmente estas notas a las/los/les estudiantes, con quienes, enseñando, aprendo; son quienes me hacen interpelar y me inducen, incesantemente, a la pedagogía de la pregunta.

Notas introductorias: coordenadas para una cartografía epistemológica de las intervenciones en el campo de lo social

La visión es siempre una cuestión del "poder de ver" y, quizás, de la violencia Implícita en nuestras prácticas visualizadoras. ¿Con la sangre de quién se crearon mis ojos? Donna Haraway, 1995

Mi comprensión de la teoría social y del Trabajo Social no puede disociarse del sentido que éstos tienen para los procesos y movimientos sociales, políticos y culturales que dinamizan las sociedades del presente, y sus incesantes búsquedas de emancipación frente a las múltiples aristas de la injusticia. La teoría social en su vertiente crítica, con el método analítico que le es inherente, nos echa una luz sobre una apuesta ética y estética que tiene implicancias en el hacer coincidir, como intelectuales socialmente responsables, lo que pensamos, sentimos, decimos y actuamos.

Es por ello por lo que apuesto a las intervenciones situadas devenidas de la ubicuidad del conocimiento; de posiciones honestamente localizadas capaces de entablar procesos de afectación y de co-construcción en materia de intervención y también en términos de investigación. Concibo la práctica investigativa y la práctica pedagógica como dos eslabones interligados, que se interpenetran e influencian entre sí. Dudo de las demarcaciones tajantes entre intervención, investigación, enseñanza, aprendizaje. Me siento constantemente desafiada a indagar los sentidos de nuestras investigaciones, intervenciones y procesos de enseñanzas y aprendizajes. En virtud de ello, 
las siguientes son apenas algunas líneas problematizadoras que me vienen resonando. Cuestiones que, desde mi situación de mujer y posición territorial en la que habito, me interpelan en términos de una resemantización y resignificación de ciertas categorías, conceptos y postulaciones que se plantean indiscutiblemente como "universales" o como verdades académicamente aceptables por la comunidad de los universitas.

Mi territorio es el aula, ya sea la formal-académica como la que se suele denominar "no-formal". Esta última la vengo transitando en espacios comunitarios en contextos territoriales de pobreza urbana, así como en instancias institucionales no-académicas de gobiernos locales que solicitan formación y capacitación con trabajadores en el complejo campo de lo social.

Los muchos años de lectura de la obra de Antonio Gramsci, me condujeron a concebir la intervención en el campo de lo social como un minucioso y empecinado trabajo cultural. Tras haber compartido cátedra con Oscar Lupori durante casi veinte años, aprendí que la intervención es la conjugación de tres dimensiones irreductibles: es trabajo, es interacción y es praxis sociopolítica. Más tarde, experiencias vividas me fueron enseñando que también, en tanto aprendemos a dejarnos afectar por el/la otrx, la intervención supone un arte. Un trabajo artístico vinculado a singularidades que se tensan con lo colectivo, en el que lo estético y lo emocional se conjugan en un abordaje de procesos complejos y, en reiteradas ocasiones, nos vemos implicados en dinámicas de enorme sufrimiento humano. En este interjuego, entablamos vínculos que transforman y, fundamentalmente, nos transforman, nos producen, nos construyen.

Cada día me pregunto acerca del sentido de las cosas que realizo. Es por ello por lo que acepto la condición ineludible de que en los territorios de nuestras intervenciones se disputan los sentidos de la verdad. La cultura, el saber académico, el conocimiento, no es atributo exclusivo de una determinada comunidad científica asentada en una posición de poder. Quienes defendemos y promovemos saberes para una vida con dignidad; quienes apostamos a los derechos humanos y a la justicia social; quienes pertenecemos a un género social y cul- 
turalmente infravalorado; quienes habitamos territorios devaluados geográfica y socialmente, somos portadores de una cultura y de saberes a los que se les ha negado el derecho de expresarse y por ello aún está la tendencia a que seamos sometidxs a vivir en una "cultura del silencio" o, en su defecto, a asimilarnos a las formas de conocimiento y práctica dominantes.

Pese a que estamos cada vez más tomadas por la racionalidad que pretende "colonizar" nuestros cuerpos, emociones y mentes, en estas líneas, defiendo la argumentación acerca del poder insustituible de los "cuerpos situados" anclados territorialmente. El territorio y los cuerpos constituyen arena de disputas políticas, de luchas y de conflictos; de configuración de poder, de cuestionamiento de la racionalidad instrumental dominante y de construcción política de lo colectivo. Son éstos y otros múltiples ejes y dimensiones los que interpelan, preguntan, interrogan nuestras intervenciones en el campo de lo social.

\section{Diálogos en tensiones}

En esta línea, deseo destacar el entrañable manantial teórico-metodológico y la fecundidad heurística que nos ofrece el pensamiento de Bajtín para la construcción de sentidos. En su bello y sugerente libro La herencia de Bajtin. Reflexiones y migraciones (2016), Pampa Aran recupera dimensiones interseccionales de este autor quien, a lo largo de su trayectoria, fuera lidiando entre lo ético, lo estético, lo epistemológico, lo lingüístico, lo histórico y lo social. Al proponer la noción de cronotopías culturales como una categoría socio-semiótica de investigación, y entendida como proceso material de producción de sentido, la autora nos introduce en una aventura intelectual posibilitadora de nuevas cartografías para las Ciencias Sociales y que pueden muy bien ser agenciadas para el trabajo en el campo de lo social.

El amplio espectro teórico desarrollado por el intelectual ruso ha extrapolado fronteras disciplinares, metodologías y campos del saber 
que abonan los discursos acerca de la cultura y sus argumentos simbólicos. Las nociones de cronotopía cultural y de comprensión dialógica, como categorías socio-semióticas de investigación, que Pampa Arán (2016) resignifica a partir de la perspectiva teórico-metodológica de Bajtin, son tópicos sugerentes para desentrañar el modo en que las formas históricas de intervenciones y prácticas del movimiento feminista abre un inconmensurable prisma teórico-metodológico que resemantiza conceptos y revitaliza categorías de análisis centrales de las ciencias sociales. Esta posibilidad despliega caminos para analizar el poder y la capacidad política de la dialéctica "cuerpo del conocimiento-conocimiento del cuerpo" (Najnamovich, 2009) en la teoría social contemporánea y en la praxis sociopolítica del trabajo en el campo de lo social.

Me sorprende el potencial político que habilita la matriz bajtiniana en tanto condensa ética, estética y política; en la que se configura el arte y la literatura como un régimen de identificación de lo sensible. No puedo desafectarme de las posibilidades que abre en términos de enseñar y aprender la teoría social y el arte del trabajo en el campo de lo social. Como docente de las aulas universitarias de un país del sur latinoamericano, este intelectual me acerca herramientas para seguir trabajando en este camino de enseñar con sentidos de emancipación en pos de desentrañar dimensiones extraordinarias de la teoría social y del trabajo social. Esto también habilita el entrenamiento aun para no comprender, en tanto esa noción de dialogismo propuesta por Bajtín, bucea por lo no conclusivo, orientándose a un nuevo mundo, no dicho y no predeterminado pero que al menos promete algo extraordinario.

En Bajtin, el "otro" es una presencia activa y concreta, de manera que, muy lejos de plantearse en términos de fusión, asimilación o sustitución, el diálogo implica fenómenos interactuantes que no pierden su integridad; crea un vínculo que, además de ser comunicativo y significativo, es expresivo y productor de sentido (Aran, 2016). De modo que siempre existen otras posibilidades; en tanto rizoma y potencia (Deleuze, 1984; Rolnik, 1994) existen otras multiplicidades de sentidos. 
Por otro lado, el feminismo (en tanto movimiento que condensa los feminismos con su diversidad-pluralidad de perspectivas) puso en el centro de la escena el cuerpo y el deseo de las mujeres y también de aquellos géneros históricamente devaluados e infra-reconocidos que se identifican con identidades sexuales no hegemónicas. Al plantear deseos y necesidades, y fundamentalmente, al poner sobre el tapete malestares, desigualdades y asimetrías de poder, el feminismo abrió nuevos desafíos e interrogantes y develó un camino para la configuración de una teoría capaz de alumbrar situaciones de injusticia en la sociedad que sin esa lente no sería posible visibilizar ni conferir objetividad.

Es interesante desentrañar algunas claves coincidentes entre Bajtin y los textos y narrativas feministas. En esta línea, entiendo que los hallazgos epistemológicos más significativos y relevantes del feminismo estriban en la conexión que ha develado entre conocimiento y poder. Como sugiere Diana Maffía (2001), más allá del sentido casi obvio de que el acceso al conocimiento trae aparejado un acceso a otros espacios de poder, el sentido más controvertido de este develamiento es mediante el reconocimiento de que la legitimación de las pretensiones de conocimiento se halla íntimamente vinculado con redes de dominación y exclusión (Fox Keller y Longino, 1996). De allí que "necesitamos el poder de las teorías criticas modernas sobre cómo son creados los significados y los cuerpos, no para negar los significados y los cuerpos, sino para vivir en significados y en cuerpos que tengan una oportunidad en el futuro" (Haraway, 1995:322). Basta el reconocimiento de la sexualidad y de los cuerpos como históricos, políticos y sociales para poder comprender las relaciones de poder que perviven en las sociedades contemporáneas.

Me pregunto incesantemente de qué modo unas lentes, como las del género, puede resignificar una mirada, resemantizar un concepto o una categoría, conferirle nuevos sentidos a una vida, otorgar otras posibilidades a un cuerpo. ¿De qué manera este faro alumbra y da objetividad a aquellos aspectos ocultos e invisibles para "la ciencia" y también para nuestras intervenciones sociales y culturales? ¿Bajo qué criterios este prisma amplía los límites de la objetividad cientí- 
fica? ¿Qué hallazgos epistemológicos más significativos ha develado el feminismo?, ¿cómo alumbra la matriz de género posibles entendimientos para desentrañar el vínculo entre conocimiento y poder y, entre conocimiento e interés?, ¿qué potencial político le subyace al feminismo? ¿De qué modo el feminismo viene transformando los valores y fundamentando el conocimiento en torno a nuestras sociedades latinoamericanas?, ¿qué capacidad tiene el prisma de género para interrogar e interpelar nuestras intervenciones en el campo de lo social?, ¿qué lenguaje utilizamos?, ¿qué postura corporal toman nuestras intervenciones?, ¿cómo y con quiénes intervenimos?, ¿cómo y con quiénes investigamos?

Deseo no soslayar que, entre los feminismos, y particularmente entre los feminismos académicos, también existen relaciones de poder y dominación que se constata por ocasiones cuando se devalúan saberes sociales colectivamente producidos; cuando se descalifican saberes producidos desde y con grupos que se encuentran en ciertos "bordes"; cuando como académicas no damos objetividad/visibilidad a ciertos procesos desconocidos y desconfiables para la "ciencia". Desacreditando estos procesos, estamos privando a la ciencia de ciertos hallazgos relevantes presentes en otras voces y en otros cuerpos resonantes que son un abono para la teoría social y para el trabajo social.

Es notorio cómo las publicaciones académicas expresan lo no dicho, y que es reflejado en el modo acerca de qué conocimientos mostramos y qué conocimientos privamos de dar visibilidad. La colonialidad del poder y del saber (Quijano, 2011; Ladner, 2011) atraviesa ciertos feminismos hasta cuando decidimos como investigadores qué artículo académico es pasible de ser publicado y cuáles de esas producciones intelectuales no son merecedoras de ese reconocimiento.

De alguna manera, cuando como intelectuales devaluamos con la puesta corporal y la palabra esas visiones y concepciones otras, esos conocimientos otros, es porque no son conocimientos y producciones intelectuales funcionales a los grupos de poder que se hallan en ciertas cúpulas de la esfera científico-tecnológica. Entonces, es constatable cómo en estas esferas, es la conveniencia (en lugar de la 
convicción) lo que mueve ciertas producciones intelectuales que se visibilizan. El estatus y el prestigio académico se jerarquizan vulnerando la justicia cultural y el derecho al reconocimiento de sectores socialmente infravalorados.

De modo que el pensamiento y la producción científica han de tener un carácter emancipador y genuino cuando pueden mostrar capacidad ética para dar lugar a esas otras voces y producciones desde el cuerpo. Es allí cuando damos lugar a posiciones políticas ancladas en la convicción. De ahí mi reivindicación inclaudicable de los conocimientos situados, esto es, de los conocimientos honestamente localizados; de esa ubicuidad entrañable del conocimiento y de la recuperación de trayectorias subjetivas pasadas por procesos de reflexividad con potencialidad de teoría. Después de todo, revelar verdades o, mejor dicho, hacer lugar a pensamientos incómodos para la teoría social, y posibilitar prácticas que van más allá del protocolo y del corset del Trabajo Social, es lo que viene haciendo la praxis política del feminismo, y también aquella que hoy es posibilitado por el descolonialismo (Hermida, 2015).

Es impresionante lo que puede un movimiento. Cuántas políticas públicas vamos logrando gracias al revitalizador movimiento feminista que es un reto para la sociedad, para la cultura y es una crítica resonante para el intelecto social.

En esta dirección, no puedo dejar de pensar y de sentir al feminismo como una fuente inagotable de producción de sentido. Producción de sentido que es potencia y rizoma que mueve la cultura; en la que el lenguaje es un medio compartido y es una arena de conflictos, tensiones y luchas de valoraciones sociales. La cultura, como el territorio en el que se disputan las políticas del sentido y sus formas institucionales y de materialización. En esta cultura, los seres humanos jugamos un papel decisivo disputando y dirimiendo el sentido de la verdad, intentando establecer su dominio hegemónico, centralizando el campo ideológico verbal en correlato con los procesos de centralización políticos sociales (Aran, 2016).

El movimiento de mujeres viene produciendo nuevos sentidos en nuestras sociedades; disputando cosmovisiones y prácticas, transfor- 
mando las sensibilidades y las representaciones sociales; reformulando prácticas políticas; creando otros modos de nombrar la realidad. Sin dudas, estos nuevos sentidos abren cuestionamientos y plantean nuevos interrogantes... también dan algunas respuestas a ciertas preguntas. El trabajo social es interrogado por esta matriz. No sólo nuestra práctica social y profesional en el campo de lo social; sino también los ejes teórico-metodológicos-epistemológicos, vinculados a los procesos de formación profesional y académica.

El Género y la escritura desde el cuerpo: las posibilidades de un prisma

El género es un campo de diferencia estructurada y estructurante, donde los tonos de extrema localización, del cuerpo intimamente personal e individualizado, en el mismo campo con emisiones globales de alta tensión.

La encarnación feminista, por lo tanto, no trata de una localización fija en un cuerpo reificado, femenino o de otra manera, sino de nudos en campos, inflexiones y orientaciones y de responsabilidad por la diferencia en campos material-semióticos de significados Donna Haraway, 1995

Me gusta metaforizar la noción de género como un prisma. La categoría de género ha sido acuñada en 1975 por la antropóloga feminista Gayle Rubín (1975) y, desde entonces, viene posibilitando hallazgos inéditos y resemantizando conceptos clásicos en la teoría social.

Lejos de ser un cuerpo teórico uniforme y de responder a un discurso homogéneo, o a identidades esencialistas que obstruyen la capacidad de ver la actualidad histórica de los seres humanos como sujetos sociales y sexuados (Boria, 2016), la epistemología feminista comprende una pluralidad de enfoques y métodos. 
Las categorías de análisis ofrecen contundencia heurística en tanto permiten captar una realidad que buscan nombrar. La categoría género opera como un prisma desde el cual mirar una realidad que desde otras teorías no sería posible visibilizar. Este prisma contribuye a elaborar argumentos para desmontar las históricas posiciones de desventaja social de las mujeres y de las otras identidades de género devaluadas e infra-reconocidas en la sociedad. Explica y comprende las causas de esta posición de subordinación y propone acciones políticas para desmontar y desactivar esos mecanismos de discriminación.

Las sociedades tienen un complejo sistema de estratificación en la que las variables de estratificación son co-extensibles (Hirata y Kérgoat, 1987), interseccionales, entramadas, en función de dimensiones adscriptas o atribuidas de las personas, y también, debido a elecciones voluntarias de éstas. Además de estar estratificadas debido a la existencia de clases sociales, configurando grupos sociales jerarquizados y asimétricos por la posición social y el uso de los recursos, también el género, la raza, la etnia, la cultura, la orientación sexual, entre otros, constituyen formas de estratificación de las que resulta la formación de grupos con problemas de subordinación social y marginación económica, política y cultural (Cobo, 2005).

Rosa Cobo es contundente al plantear que las construcciones sociales cuya legitimación y normatividad es su origen natural son las más difíciles de desmontar con argumentos racionales, pues aparecen con el prejuicio de formar parte de un "orden natural de las cosas", fijo e inmutable, sobre el que nada puede hacer la voluntad humana. Sin embargo, una vez que ha mostrado una elocuente capacidad para desentrañar ejes de desigualdad, asimetría y opresión, el prisma de género se ha convertido en un parámetro científico irrefutable para las Ciencias Sociales (Cobo, 2005).

Lidia Cirilo (2005) señala que la ausencia de perspectiva y parámetros de género torna un conocimiento dudosamente fiable. De este modo, el género es una lente teórica, metodológica, analítica y política a través de la cual podemos examinar y transformar instituciones, culturas y prácticas, incluyendo las representaciones sociales y las creencias culturales. En tanto llave categorial teórica, el género está 
dotado de un valor heurístico. Este prisma es un poderoso instrumento develador, revelador e iluminador de las asimetrías y las relaciones de poder que se configuran en la sociedad.

El feminismo ha desplegado una mirada política y una hermenéutica a dimensiones de la realidad social que otras teorías no habían sido capaces de realizar, al "des-cubrir" aquellas estructuras y mecanismos que reproducen la discriminación, segregación o exclusión de las mujeres en diversos espacios de la sociedad (Cobo, 2005a). En virtud de ello, categorías como división sexual del trabajo, segregación ocupacional debido al género, segmentación del trabajo según el sexo, trabajo productivo, trabajo reproductivo, trabajo doméstico, calificaciones laborales, impuesto reproductivo, acoso laboral y violencia de género, el uso del tiempo como factor de desigualdad han sido contribuciones importantes del feminismo. Estas categorías son a la vez analíticas y políticas en tanto, además de enriquecer sobremanera la teoría social contemporánea, ofrecen claves para las transformaciones hacia mayores alcances de justicia e igualdad. Y el Trabajo Social ha de agenciar estos nuevos retos para los procesos de intervención y para sus contenidos y metodologías curriculares.

El potencial teórico-metodológico y epistemológico de los feminismos nos viene mostrando que muchas de sus categorías creadas, entre ellas la de "género" son inestables y sometidas a un permanente debate, recreación y reconversión. La paradigmática obra de Judith Butler (1999) denominada Género en Disputa problematiza el modo en que las prácticas sexuales no normativas cuestionan la estabilidad del género como categoría de análisis. A su vez, esto produce una crisis en la ontología experimentada en el nivel de la sexualidad y del lenguaje. Al plantear que la univocidad del sexo y del género son ficciones reguladoras que refuerzan y naturalizan los regímenes de poder convergentes de la opresión masculina y heterosexista, Butler cuestiona la estabilidad de la categoría género en tanto premisa principal de la política feminista. Enfatiza la necesidad de una nueva política feminista para combatir las reificaciones mismas de género e identidad, que sostenga que la construcción variable de la identidad es un requisito metodológico y normativo, además de una meta po- 
lítica (Butler, 2007:53). Al desentrañar, entre múltiples aspectos, la reconocida tesis de Simone de Beauvoir "No se nace mujer, sino que se hace", Butler argumenta que el género, lejos de ser producto y productor de un determinismo social inexorable, es un constructo inacabado, siempre abierto a posibles dilucidaciones. De modo que los feminismos negros, latinos, de diversos grupos minoritarios dieron lugar al reconocimiento interno de la categoría "género" y crearon la necesidad de comprender las diversas formas en que se dirime y se resignifica en cada contexto.

En esta línea, el análisis feminista en torno a la opresión de género se ve constantemente conmovido y reconfigurado mediante la confluencia con otros ejes de diferenciación. Esta condición permite visibilizar la interconexión entre múltiples formas de dominación y opresión (raza, etnia, clase, sexualidad, corporeidad, nacionalidad, edad) que intervienen conjuntamente y de modo diferenciado entre las mujeres. Esta cosmovisión problematizadora, vinculada a la variación de la categoría género, emergió de las reivindicaciones de las feministas de color hacia las mujeres feministas blancas, de clase media, heterosexuales, habida cuenta de la multidimensionalidad de los aspectos que sostienen la opresión. Esta perspectiva interseccional luego será recepcionada por las críticas poscoloniales y también decoloniales de las representaciones occidentales de las mujeres oprimidas del "tercer mundo" en la que se replantea el debate de la diferencia cuestionando el modelo de sujeto feminista construido en base a los cánones de la mujer occidental, blanca, de clase media y heterosexual (Gandarías, 2014).

Asumir un prisma feminista e interseccional abre la posibilidad de crítica a las representaciones occidentales del "otrx" y permite una visibilización de la diversidad de experiencias y condiciones materiales de lxs sujetxs entramados en los contemporáneos procesos de globalización/mundialización del capital.

Para el feminismo, como teoría crítica de la sociedad, los conceptos no sólo iluminan y explican la realidad social, sino también, politizan y transforman esa realidad. Esa realidad que se transforma, a su vez, interpela conceptos y categorías desafiándonos a nuevos cons- 
tructos teórico-metodológicos-epistemológicos. Como señala Celia Amorós (2008), en feminismo conceptualizar es siempre politizar. En esta línea, las prácticas teóricas son, indefectiblemente, prácticas políticas (Boria, 2016). En definitiva, iluminar la realidad con nuevas lentes, disponer otros prismas, abrir nuevos conceptos y categorías supone un campo de lucha y de posiciones de poder. Es por esta razón que el prisma de género ha hecho tambalear la teoría social porque hizo resignificar y resemantizar muchos de los conceptos; ha creado nuevas categorías analíticas y ha desplegado otras cartografías y nuevas coordenadas en la práctica de investigación.

En consecuencia, no podemos aislar del plano de afectación al trabajo social. Los feminismos hoy interpelan profundamente e interrogan sobremanera el modo cómo enseñamos, investigamos e intervenimos en el campo de lo social.

\title{
Cuerpos situados, conocimiento político
}

\author{
No existen fotografías no mediadas ni cámaras \\ oscuras pasivas \\ en las versiones científicas de cuerpos y máquinas, \\ sino solamente posibilidades visuales altamente \\ específicas, \\ cada una de ellas con una manera parcial, activa \\ y maravillosamente detallada de mundos que se \\ organizan
}

Donna Haraway, 1995

Es indudable que el feminismo viene mostrando una singular capacidad para reconfigurar visiones y abrir nuevas perspectivas teóricas así como el despliegue de herramientas a partir de las cuales comprender e intervenir. Una de las contribuciones más vitales del feminismo al objetivismo científico fue situarlo, es decir, desentrañar la operación ideológica que supone esgrimir la noción de objetividad en la ciencia. 
Quienes acompañan esta opción teórico-metodológica acentúan que situar el conocimiento supone recuperar la ciencia como afecto y como poiesis estética. Kristeva (1974) apunta que este proceso trae consigo una lógica de revuelta —íntima-, negatividad y finalmente de transposición del orden tético (simbólico) (Fígari, 2011). Ocurre algo del orden de la irreverencia en el proceso de investigar en el que los protocolos cientificistas pueden ser útiles, pero nunca suficientes para comprender. En esta línea de análisis, es vital la centralidad que asume la comprensión para el feminismo, en tanto aloja positivamente el reconocimiento de los afectos y las pasiones en el proceso de cognición.

La idea de conocimiento situado rompe con la noción de sujeto epistemológico abstracto. Para Donna Haraway (1995), situar el conocimiento implica reconocer los posicionamientos múltiples de quien conoce; en tanto cada quien se encuentra en una compleja trama de posiciones, identidades y puntos de vistas múltiples, inestables, incluso contradictorios y cargados de relaciones de poder. De este modo, los cuerpos visibilizan las diferencias en las relaciones de poder.

Como mujer y desde su cuerpo Donna Haraway (1995) argumenta que las mujeres somos las que tenemos cuerpo, las marcadas, las que construimos desde una posición no objetiva e interesada, de forma que se nos prohíbe (no) tener un cuerpo, de análoga manera que se nos inhabilita para poseer un punto de vista o un prejuicio en cualquier discusión. En esta línea, las mujeres no podemos conocer "objetivamente" porque tenemos cuerpo y es por esa razón que conocemos desde nuestra sesgada y parcial subjetividad. En cambio, el conocimiento "objetivo", (vale decir, "científico", "confiable") que ellos postulan es un conocimiento sin cuerpo, desencarnado, sin tiempo ni espacio.

Es menester destacar que la perspectiva parcial que Haraway reivindica es la que promete una visión objetiva, lo que no equivale abrazar a un posicionamiento relativista. El relativismo absoluto apunta la autora - también es un gesto colonizador en tanto unifica la experiencia del desconocimiento tanto como el objetivismo lo hace 
con relación al conocimiento pleno ("manera de no estar en ningún sitio mientras se pretende estar igualmente en todas partes"). La autora resalta su convicción de que la alternativa al relativismo son los conocimientos parciales, localizables y críticos, que admiten la posibilidad de conexiones llamadas "solidaridad en la política y conversaciones compartidas en la epistemología” (Haraway, 1995:333).

Argumentando su posición, Haraway apunta que el feminismo se resiste a toda forma de simplificación. Es en las perspectivas parciales donde se encuentra la posibilidad de una búsqueda objetiva, sostenida y racional. Al contrario de desestimar la noción de objetividad, Donna Haraway la resemantiza, la resignifica y le confiere un sentido inédito en el acto de investigar. Resemantización que asume buscar la perspectiva desde puntos de vista que nunca conoceremos de antemano, pero que prometen algo extraordinario. Esta es una condición indispensable que confluye con otros movimientos de indagación en la que la co-construcción de conocimientos puedan ser capaces para con-formar mundos menos organizados en torno a ejes de dominación y de desigualdad. Esta cuestión es clave en materia de intervención en el campo de lo social, en tanto ciertos protocolos pueden ser una referencia, pero nunca un corset en el que podamos acomodarnos incuestionablemente ni indefectiblemente.

De modo que esa topografía de la subjetividad es multidimensional y polifónica de la misma forma que la visión. El yo que conoce es parcial en todas sus facetas; nunca terminado ni total, ya que no se encuentra simplemente ahí y en estado original. Está siempre construido y remendado de manera imperfecta y, por lo tanto, es capaz de unirse a otro, de ver junto al otro, sin pretender ser el otro. Es ese dialogismo tenso, en fricción; ese estado de puntos de vistas en suspensión de voces distintas y por veces discordantes, de análoga manera en que sugiere Bajtín (1982).

Solamente la perspectiva parcial promete una visión objetiva, en tanto la objetividad feminista trata de la localización limitada y del conocimiento situado, es decir, el carácter situado de una mirada. De este modo, los cuerpos situados solo producen conocimiento político. La autora alerta que los esquemas que limitan el conocimiento, al ser 
teorizados como actitudes de poder, inhiben planteos que buscan la verdad (Haraway, 1995).

Asimismo, Haraway es consciente del riesgo que supone "romantizar" desde las posiciones subalternas, incluso si "nosotras" habitamos "naturalmente" el gran terreno subterráneo de los conocimientos subyugados. No obstante, destaca que del mismo modo se pretenden conocimientos universales "cientificistas” desde ningún lugar. Apunta que los puntos de vista "subyugados" son los que parecen prometer versiones transformadoras más adecuadas, sustentadas y objetivas del mundo. Sin embargo, es importante atender a esas "pericias" con los cuerpos y con el lenguaje del mismo modo con el que pretenden las “más altas visualizaciones tecnocientíficas” (Haraway, 1995:378). Para la autora, las posiciones de los subyugados no están exentas de re-examen crítico, de descodificación, de deconstrucción ni de interpretación, es decir, de los dos modos hermenéuticos y semiológicos de investigación crítica. Los puntos de vista de los subyugados no son posiciones "inocentes". Al contrario, son preferidos porque en principio tienen menos posibilidades de permitir la negación del núcleo interpretativo y crítico de todo conocimiento (Haraway, 1995; Fígari, 2010).

Es por ello por lo que la cuestión de la ciencia en el feminismo trata de la objetividad como racionalidad posicionada. La introducción del prisma feminista en las ciencias sociales ha tenido como consecuencia la crisis de sus paradigmas y la redefinición de muchas de sus categorías analíticas. Seyla Benhabib (1990) señala que cuando las mujeres entran a formar parte de las ciencias sociales, ya sea como objeto de investigación o como investigadoras, se tambalean los paradigmas establecidos y se cuestiona la definición del ámbito de objetos del paradigma de investigación, sus unidades de medida, sus métodos de verificación, la supuesta neutralidad de su terminología teórica o las pretensiones de universalidad de sus modelos y metáforas.

Sus estudios han podido dar visibilidad al modo en que las concepciones y prácticas hegemónicas de atribución, adquisición y justificación del conocimiento perjudican sistemáticamente a las mujeres, y también, a otros colectivos devaluados socialmente favoreciendo 
procesos reproductores de injusticias y desigualdades. Por ello, asumir la contribución de las mujeres en la ciencia es ampliar los propios horizontes de búsqueda del conocimiento, lo que supone una apertura de emancipación no solo para las identidades femeninas sino también para las masculinidades.

Análogamente, el prisma feminista ha de seguir tambaleando y desafiando las prácticas de intervención en trabajo social; sus lógicas, sus modos de desempeño profesional, sus métodos y metodologías de intervención, el lenguaje que utilizamos, los mandatos socioculturales que reproducimos, la puesta corporal que ensayamos.

\title{
Cronotopía Cultural como categoría socio-semiótica de investigación-intervención. Su agenciamiento para el feminismo y para el Trabajo Social
}

\author{
La forma es una frontera trabajada estéticamente [...] \\ Se trata tanto de la frontera del cuerpo, \\ como la del alma y del espiritu (orientación del \\ sentido) \\ Bajtin, 2015
}

Guilles Deleuze (1984) nos habla del agenciamiento en tanto multiplicidad que comporta un espectro variado de géneros en el que se entablan uniones y relaciones entre los mismos y en el que se resaltan las alianzas y aleaciones entre estos segmentos diferentes. En la producción de enunciados no hay sujetos, sino que hay agentes colectivos en tanto los seres humanos agenciamos signos y cuerpos como piezas heterogéneas de una misma máquina $\mathrm{y}$, de este modo, nos vamos constituyendo como variables de la función en la que conjugamos incesantemente valores y segmentos.

A partir de la categoría cronotopo Bajtín recupera la conexión interseccional de relaciones temporales y espaciales asimiladas artísticamente en la literatura (1989: 237). El intelectual ruso acuña la categoría “cronotopo artístico literario" para referirse a modo en que la 
creación verbal y, específicamente, el género de la novela, conforman la percepción de la dinámica del tiempo en el espacio a partir de posiciones enunciativas concomitantes, pero diferenciadas, del autor y del lector como sujetos dialógicos tangencialmente situados con la obra (Arán, 2016). El material novelesco —lejos de ser estático e inertees hablante, significativo y semiótico. Los hechos están localizados; irrumpen y ocupan un determinado espacio. De modo que, en esta categoría, que es heurística y metodológica, el tiempo se condensa, se comprime; se torna visible desde el punto de vista artístico. Y a su vez, el espacio se intensifica, penetra en la dinámica del tiempo, del argumento, de la historia. De manera que los elementos del tiempo se revelan en el espacio; y el espacio es entendido y medido a través del tiempo. De esta forma se constituye el cronotopo artístico.

Es sugerente el modo en que Pampa Arán (2016) actualiza esta categoría bajtiniana hacia la problematización de nuestra cultura sociopolítica. De acuerdo con la autora, el cronotopo, en tanto categoría epistemológica y metodológica, posibilita describir e interpretar formas modelizantes de la dinámica cultural de colectivos sociales cuya experiencia está indisolublemente asociada a los espacios, a las identidades y, en términos de Castoriadis (1997), a los imaginarios. La autora señala que, aunque las formaciones sociales cronotópicas constituyen procesos de la dinámica cultural, su designación, en cambio, es un metalenguaje, es decir, una categoría descriptiva, condensadora para ciertos fenómenos sociales espacio-temporalizados que se interpretan como relatos situados y se leen como textos (Arán, 2016:154). Asimismo, el cronotopo encarna (del mismo modo que la noción de polifonía) esa idea bajtiniana de que las versiones hegemónicas y monolingües ("la lengua única de la verdad") siempre tratan de acallar las tensiones y las contradicciones sociales que la novela, en cambio, intenta desnudar (Arán, 2016:145). En teoría social, podemos pensar en esas versiones dominantes que aparecen como el pensamiento único. Pensamiento dominante que vela aquellas otras voces y prácticas disidentes y subalternas, que contradicen, y ponen en tensión y en conflicto, los postulados hegemónicos y sus prácticas políticas de legitimación del poder. En trabajo social, análogamen- 
te, lo podemos pensar en términos de formas protocolares de intervención que, lejos de plantearse como referencias, funcionan como modos predeterminados que se cierran en sí mismas, negando otras posibles intervenciones, en las que se pueda conjugar la tensión de lo singular y lo colectivo.

El feminismo, como voz contestadora de la realidad, como protesta a las erráticas y a las insuficientes políticas públicas que serían necesarias para la trama de la sociedad; y como crítica a las formas en que la teoría social intenta explicar y comprender la realidad, viene generando nueva producción de sentidos.

Un analizador de lo que estoy argumentando como formas históricas de intervención y como práctica que irrumpe la normalidad en el espacio público se halla vinculado con $\mathrm{Ni}$ Una Menos; movimiento que vienen proponiendo las organizaciones de mujeres e identidades sexuales no hegemónicas para darle objetividad a los crímenes en razón del sexo; y para conferir visibilidad a los diversos modos en que está institucionalizada la violencia y los micromachismos más sutiles en la sociedad.

Las múltiples formas expresivas del movimiento Ni Una Menos busca entramarse en un proceso cultural de producción de sentido, de ocupación y de emplazamiento del espacio público y se aloja en el imaginario social como experiencia colectiva del espacio. El movimiento ocupa el espacio público, trasladando hacia esta esfera un problema grave vinculado a la tan velada y naturalizada violencia de género y a los feminicidios que se suceden en el ámbito de la intimidad y que otrora fueran caratulados como crimenes pasionales. Más aun, estas intervenciones urbanas tienen un carácter prismático en tanto disparan en la sociedad, y en cada uno de los sujetos que la conforman, una multiplicación de interpretaciones y sentidos.

Reconocer y valorar las luchas que vienen entablando los movimientos y organizaciones de mujeres $\mathrm{Ni}$ una Menos, en las que se da objetividad al femicidio y a las múltiples formas de violencia y desigualdad debido al género; en las que se muestra cómo las relaciones sociales de género son relaciones políticas y de poder; constituye una crítica concreta al androcentrismo - desde los cuerpos situados 
como cuerpos políticos. Esto es, una crítica al patriarcado como forma civilizatoria y cultural basada en estructuras naturalizadas y normalizadas/normativizadas de poder y dominación de un género (masculinidad hegemónica) sobre las otras identidades sexo-genéricas infra-reconocidas y aun devaluadas por el conjunto social.

También cronotopías como el Paro de Mujeres que, de múltiples formas busca conferir objetividad a la feminización de la pobreza, a las asimetrías existentes en términos de tareas y remuneraciones en el trabajo productivo, a la feminización del trabajo doméstico y del cuidado - sean éstos de carácter remunerado o no remunerado. Estas asimetrías en el ejercicio del trabajo productivo y reproductivo dan objetividad a un tema central des-cubierto por la economía feminista: el uso del tiempo como factor de desigualdad entre los géneros.

Estos analizadores que vengo proponiendo constituyen cronotopías en tanto que irrumpen en la normalidad resignificando y condensando tiempo y espacio. Cronotopías en tanto son producto de acciones y de prácticas reiteradas e insistentes (verbales, no verbales; con expresiones desde el cuerpo, con intervenciones urbanas, desde el arte, desde la protesta social, desde la puesta del cuerpo en transgresión) sobre emplazamientos como la calle, la plaza en el que se producen nuevas concepciones políticas, culturales, económicas, históricas. Van proponiendo una nueva cultura; constituyen apuestas a nuevas prácticas que logran inscribirse en la vida cotidiana de muchas mujeres y van logrando transformaciones en el universo simbólico y en las prácticas concretas de la organización familiar y laboral. Esto supone la producción de otras modelizaciones, otros imaginarios, otras representaciones sociales y cosmovisiones.

Paulatinamente, como respuesta a estas cronotopías del movimiento organizado de mujeres se van instalando políticas públicas que van reivindicando el derecho a la identidad de género. Se va labrando una construcción de la agenda pública con la apuesta firme de intervenir en las relaciones sociales de géneros hacia modos más simétricos en las oportunidades y en el ejercicio del poder. Y con una apuesta hacia la concreción de políticas dotadas de justicia social 
(esfera redistributiva), cultural (esfera del reconocimiento) y política (esfera de la representación) (Fraser, 2009).

Estos cronotopos condensadores de sentidos dan cuenta de lo complejo, de la polifonía de signos, de la multiplicidad de sentidos; de lenguajes corporales y gestuales. Ahora bien, ¿de qué modo la teoría social viene captando estos núcleos de significación? ¿Qué nuevas cartografías se va configurando a partir de las nuevas voces resonantes que irrumpen el espacio público? Esa polifonía que se entrama en diálogos que son tensos y conflictivos, pero también sororos y cordiales —con prácticas instituyentes transgresoras, pero también convivientes con lógicas reproductoras-instalan nuevas representaciones sociales en el conjunto social. ¿De qué modo estos escenarios enunciativos del amplio espectro que configuran los feminismos vienen siendo un abono vital para la teoría social contemporánea? ¿De qué manera el trabajo social latinoamericano es interrogado por este movimiento?

\section{Consideraciones finales... para otras aperturas}

El conocimiento de una misma requiere una tecnología semiótica que enlace los significados con los cuerpos

Donna Haraway, 1995

El feminismo, en su dimensión de tradición intelectual, ha mostrado que el conocimiento está situado y que cuando un colectivo social está ausente como sujeto y como objeto de la investigación, a ese conocimiento le falta objetividad científica. La teoría feminista ha puesto al servicio de la sociología crítica una hermenéutica que ha develado las invisibles relaciones de poder de la masculinidad hegemónica sobre las mujeres y las otras identidades de género infrareconocidas en nuestra sociedad. Al mostrar los nudos conflictivos de la subordinación y advertir sobre su dimensión normativa, se ha 
convertido en parte ineludible de cualquier teoría del cambio social (Cobo, 2005).

Por otra parte, la categoría bajtiniana de cronotopo histórico real (apud Arán, 2016:150) es de enorme vitalidad heurística para comprender algunas configuraciones de la experiencia colectiva y del proceso cultural de ocupación del espacio público que el movimiento de mujeres viene manifestando y expresando denunciativamente en nuestro país durante la última década. Dichas intervenciones colectivas vienen interpelando incesantemente a la teoría social y, por ende, al trabajo en el campo de lo social. También dan visibilidad a las erráticas políticas públicas y a las inexistentes políticas en torno a la prevención en violencia de género. En función de ello, la investigación acción participativa, la co-producción de conocimientos, los procesos interactivos, dialógicos, performativos de intervención, hoy han de ser indispensables para continuar con la transformación política de la sociedad.

Hemos de reconocer la interacción del espacio y del tiempo como constitutivos de toda experiencia humana, y como dimensiones ineludibles de las experiencias colectivas en particular (Sassen, 2003). En esta línea, las experiencias colectivas denunciativas en el espacio público irrumpen en la normalidad en el contexto de una coyuntura sociopolítica determinada. En términos de Pampa Arán (2016), el espacio público deviene así producto a la vez que productor de experiencias identitarias sociohistóricas. A propósito de la categoría cronotopías culturales, la autora nos advertirá que "el espacio en su materialidad no puede interpretarse acabadamente fuera del tiempo y el tiempo es cronología, devenir, cambio; entre ambos hay una intervinculación esencial (Bajtin, 1989). De modo que parecería que la percepción humana cotidiana está vinculada a cuestiones de visibilidad espacial y marcos cognitivos temporales (Arán, 2016:151).

En esta cartografía, nuevas gramáticas de intervención y otros modos de agenciamiento se erigen en el espacio público resignificando la vieja consigna feminista lo personal es político. Lo íntimo es político, es lo que de algún modo nos actualiza el movimiento $\mathrm{Ni}$ Una Menos. A través de sus intervenciones identitarias, este movimiento, 
instala nuevas retóricas narrativas: la de la violencia de género; la de la discriminación debido al sexo, la de la feminización de la pobreza y de la precariedad laboral, la de la centralidad de las mujeres en el ámbito doméstico del hogar. De la misma manera, instaura otros conocimientos en la sociedad; en el sentido común, en sus representaciones sociales. Algo de los conocimientos situados que se relatan como textos irrumpen en la conciencia de la sociedad.

Hemos también de insistir que las prácticas situadas de investigación y de intervención abren la posibilidad de revertir la lógica del sesgo colonialista del saber y del poder en torno a las prácticas en el campo de lo social (Quijano, 2011; Ladner, 2011; Hermida, 2015). Asimismo, coloca en evidencia el tinte androcéntrico y patriarcal, y supuestamente neutro, de la construcción del conocimiento, e instalan la cuestión del histórico vínculo entre saber y poder; y entre conocimiento e interés. Estos modos desnudan el carácter inacabado y provisorio del conocimiento y, por tanto, nos revela la construcción permanente de conocimientos y modos de desempeño de prácticas sociales y profesionales, en constante proceso de revisión y producción.

Fígari (2011) sugiere que asumir posicionamientos en la actitud de investigar torna posible evidenciar la contingencia de los conocimientos que condensan poder configurando cuerpos y objetos y los modos históricos de producción de estos. Vale decir, la decodificación, reconstrucción e interpretación crítica como métodos privilegiados de la objetividad situada. Para ello, de acuerdo con Sandra Harding (1993) han de ser vitales las descripciones de las experiencias otras y las formas en que estos sujetos lidian con su realidad y cómo construyen sentidos.

Para Bajtín (2015), vivir significa ocupar una posición valorativa en todo momento de la vida. De modo que establecerse axiológicamente supone que el yo y el otro tornan posible cualquier valoración real, tanto en el acto ético como en cada vivencia y sensación.

Ocupar un lugar y ser consciente de la posición que se asume, implica responsabilidad política de nuestras prácticas. De manera que si el conocimiento es situado puede comprometerse. Esto nos induce a revisar nuestras prácticas semióticas en la producción de conoci- 
miento, lo que involucra un espectro de dimensiones que van desde la imposición metodológica hasta la interpretación, comprensión y comunicación de significados. Supone auditar también nuestras lógicas de intervención y construcción de la praxis sociopolítica.

Producir conocimiento supone situarse en un campo de batalla que, mediante la persuasión encarna en "prótesis significantes", es decir, en mundos de objetos retóricos hechos cuerpo (Haraway, 1995; Fígari, 2011). En la ciencia, las matrices teórico-metodológicas son herramientas que producen modificaciones en el mundo. Una pregunta puede habilitar una multiplicidad de reflexiones y de acciones políticas. En esta línea, es apenas ilusoria la separación entre comprender e intervenir (Fox Keller, 2000). De allí que es importante resaltar que el prisma de género, como categoría política propuesta por el feminismo, tiene un indiscutible compromiso con la igualdad y con el cambio social.

Carlos Fígari (2011) habla de la ciencia como experiencia amorosa, en tanto la relación situada es siempre cuerpo a cuerpo y no aquella falacia sujeto-objeto con el que pretende conferir regulación el objetivismo cientificista en tanto éste postula una supuesta validez universal de enunciados y metodologías.

El autor apunta que la propia experiencia del encuentro en el que acontece conversación-transferencia-silencio-mirada engendra una obra/texto basada en las salidas momentáneas de sí, de las categorías naturalizadas del mundo y de nuestras autopercepciones. Palpar ese fuera-de-sí, esa "salida" de lo simbólico a lo semiótico (lo imaginario) puede captarse en clave emocional. De allí que el autor trae la instigante reflexión de Fox Keller (1991) sobre la percepción alocéntrica y la afectividad creativa en la ciencia, de la cual injustamente se la ha despojado (relegándola al mundo de lo no político, acientífico, femenino). Una percepción alocéntrica refiere al cuidado del otro; y no puede simplificarse al "consentimiento informado contractual". De modo que no existe el propósito de "sacar" información sino de co-producirla. Por lo tanto, quien se sitúa como investigador(a) acompaña, escucha, da soporte y soporta, ríe, pone el hombro, abraza, 
guarda silencio, habla, transmite o comunica y si es necesario, no dice nada (Fígari, 2011:10).

De alguna manera, el conocimiento situado sale del lenguaje para colocarse en una experiencia entre quien investiga y el otro. Se habilita un canal erótico vinculado a la afectividad y un canal estético como experiencia creativa. Salir del lenguaje supone no dejar de usarlo sino intentar metaforizar experiencias en el campo de lo fantástico y de lo poético, habilitar el juego y la experiencia amorosa y singular del encuentro. Supone recuperar narrativas de quiebre y continuidad. Comunicar por resonancias, como experiencias entre cuerpos para las cuales la vida no prepara (Bachelard, 2010; Fígari, 2011) Esta condición se adquiere mediante entrenamiento en la sensibilidad.

Por otro lado, leer y desentrañar lo semiótico en lo tético (lo imaginario en lo simbólico), además de condensar acuerdos que producen sentidos y categorías para interpretar, apunta a mantener sujetos descentrados y contradictorios, capaces de articular, de sumarse a otros, conectarse, juntarse. Apoyarse nuevamente sobre la parcialidad y no la unidad en pos de ser objetivos. Esto supone habilitar un ejercicio de una racionalidad utópica a partir de heterotopías capaces de presentar mundos mejores y concomitantemente, una crítica a las prácticas de dominación y de denuncia de formas de opresión. Estas líneas generan obras abiertas que a su vez posibilitan lugares ontológicamente seguros de habitar (Fígari, 2011; Haraway, 1995).

Asumiendo que la posición feminista no es la única, porque como sugiere Haraway, nuestros mapas y cartografías requieren de otras dimensiones para que esa metáfora posibilite fundamentos a nuestras miradas, entendemos que la finalidad de una epistemología y de una política de los posicionamientos responsables y comprometidos, han de generar canales hacia mejores versiones del mundo y de "la ciencia”. En esta línea, entiendo que el feminismo ha develado hallazgos epistemológicos, teóricos y metodológicos, lo que indefectiblemente habilita su potencial político de transformación permanente. Su contribución ha de aventurarnos a hacer de nuestra intervención en el campo de lo social una interacción y una praxis sociopolítica íntimamente vinculada a una experiencia compartida y amorosa. 
Como muy bien nos comparte en un bello texto nuestra colega Raquel Rubio (2016), parafrasenado a Zito Lema (2001) quien expresa que es "imposible dejar de lado nuestros sentimientos, nuestras emociones, la mirada con que se nos presenta el mundo, la realidad que moviliza a la sociedad en un proceso histórico determinado". La autora instiga a "poder intervenir desde una producción deseante. Esto implica afectarse con el (aprendizaje) ejercicio de la profesión, como modo de resistencia a la rutinización, la alienación y a los efectos siniestros que esto produce en las subjetividades. Consiste en animarse a producir interferencias en la habituación, fabricar rupturas con lo monótono. Esto es posible si nos ilusionamos con ir al rescate del hacer (poiesis)" (Rubio, 2016:101).

Entonces, son sugerentes estas palabras como líneas de fuga de una burocracia que tiende a dejarnos "atrapadas sin salida" y a sumirnos en el conformismo y en la resignación; y por ende, en la negación de los afectos y de la política en nuestros modos de intervención en el campo de lo social. Desentrañar los sentidos que alojan esxs sujetxs con quienes intervenimos es un desafío cotidiano para garantizar la dignidad en los procesos de desempeño del trabajo en el campo de lo social.

Es por ello que hemos de considerar importantes los protocolos de intervención, pero nunca suficientes. Los protocolos han de ser una referencia, pero de ningún modo un corset que estrecha y empobrece los canales de actuación del Trabajo Social. Los protocolos han de ser vitales y no obturadores. Han de ser cuestionadores de la coexistencia ineludible entre la macro y la micropolítica. La pedagogía del feminismo nos posibilita llaves, nuevas aperturas, preguntas, disrupciones, comprensiones. Nos induce a deconstruir intervenciones mecanizadas que mutilan la potencia en cada sujetx. Conferir "objetividad" a las situaciones singulares que se abordan en el trabajo de intervención es un reto y una apuesta ineludible para el trabajo social. Apelar a las narrativas de lxs sujetxs en clave de encuentro cuerpo a cuerpo-conversación-silencio-mirada, nos induce a indagar acerca de los sentidos que les dan a sus acciones; a reconocer su universo de sufrimientos y padecimientos; a explorar su mundo simbólico y ma- 
terial. Esta capacidad de habilitar el tránsito por estas dimensiones es lo que garantiza que la intervención consiga esa meta esperada. De otro modo será tan sólo un objetivo profesional que ha de cumplirse sin implicarse con el cuidado del otrx.

Nos encontramos desafiadas a descubrir grietas y flujos que entraman veladamente esos campos de actuación del abordaje de lo social. He aquí algunas líneas sugerentes canalizadoras para potenciales prácticas e intervenciones que nos prometen, al menos, algo extraordinario. Quedan nuevas preguntas que a su vez desafían a redoblar la apuesta por intervenciones sensibles al feminismo. Dejo abierto el desafío - como motor mismo de la creación de sentido- para interpelar nuestras prácticas pedagógicas, investigativas e interventivas, $y$, en lo posible, para desentrañar mediante narrativas, algunos trazos posibles que (nos) impliquen en un entrecruzamiento práxico con las coordenadas abiertas por los feminismos.

\section{Bibliografía}

AMORÓS, C. Mujeres e imaginarios en la globalización. Rosario, Homo Sapiens, 2008.

ARAN, P. La herencia de Bajtin. Reflexiones y migraciones. Córdoba, UNC/CEA, 2016.

BACHelard, G. Poética del espacio. México, Fondo de Cultura Económica, 2010.

BAJTIN, M. Estética de la creación verbal. México, Siglo XXI, 1982.

"Las formas del tiempo y de cronotopo en la novela. Ensayos sobre Poética histórica, en Teoría y Estética de la novela, Madrid, Taurus, 1989, pp. 237-410.

BEAUVOIR, S. El segundo sexo. Madrid, Cátedra, 2005.

BENHABIB, S. "El otro generalizado y el otro concreto: controversia Kolhberg-Gilligan y la teoría feminista", en Seyla Benhabib y Drucilla Cornell (Eds.) Teoría feminista y teoría crítica. Valencia, Alfons El Magnanim, 1990.

BIDASECA, K. Vivas nos queremos. Buenos Aires. Milena Caserola editora, 2017.

BUZAGLO, A.; MORANDI, M. y SOSA, R. "Epistemologías feministas y decolonialidad interpelando a la teoría social contemporánea. Problematizaciones del saber y del poder 
en la producción de conocimientos". Panel presentado en el I Congreso Latinoamericano de Teoría Social. Buenos Aires, 2015.

BORIA, A. "La comprensión dialógica. Una ética para la teoría feminista", en Aran, P. La herencia de Bajtin. Reflexiones y migraciones, Córdoba, UNC/CEA, 2016, pp. 161-172.

BUTLER, J. Géneros en disputa. El feminismo y la subversión de la identidad. Buenos Aires, Paidós, 2007.

CIRILLO, L. "Virtualidades pedagógicas del feminismo para la izquierda", en Revista Internacional de Filosofía Política, N²5, UNED-Madrid/UAM-México, 2005, pp. $33-45$.

CASTORIADIS, C. "El imaginario social instituyente" en Zona Erógena (1997-35) Disponible en: http://www.ubiobio.cl/miweb/webfile/media/267/Castoriadis\%20 Cornelius \%20-\%20El\%20Imaginario\%20Social\%20Instituyente.pdf Accesado el 4/5/2017.

COBO BEDIA, R. "El género en las Ciencias Sociales”, en Cuadernos de Trabajo Social, 2005a, Vol 18, pp. 249-258.

"Globalización y nuevas servidumbres de las mujeres", Amorós, C. y De Miguel, A. (Eds.), Teoría feminista: de la Ilustración a la globalización, tomo 3, Madrid, Minerva, 2005b.

DELEUZE, G. Rizoma. Pre-Textos, Valencia, 1984. Disponible en: http://www.fen-om. com/spanishtheory/theory104.pdf Accesado el 10/6/17.

FÍGARI, C. "Conocimiento situado y técnicas amorosas de la ciencia. Tópicos de epistemología crítica”, 2010. Disponible en: https://epistemologiascriticas.files.wordpress. com/2011/05/figari conoc-situado.pdf Accesado el 9/5/16.

FOX KELLER, E. y LONGINO, H. Feminism \& Science, Oxford: Oxford University Press, 1996.

FRASER, N., Scales of Justice. Reimagining Political Space in a Globalizing World, New York, Columbia University Press, 2009.

GANDARIAS GOIKOETXEA, I. Tensiones y distensiones en torno a las relaciones de poder en investigaciones feministas con producciones narrativas. Quaderns de Psicologia, 16(1), 127-140; 2014. Disponible en: http://dx.doi.org/10.5565/rev/ qpsicologia.1210

GRAMSCI, A. Antología. Madrid, Siglo XXI, 1988.

HARAWAY, D. Ciencia, cyborgs y mujeres. La reinvención de la naturaleza, Madrid, Cátedra, 1995. 
HARDING, S. "Rethinking Standpoint Epistemology: What is Strong Objectivity?" En L. Alcoff y E. Potter (Eds.) Feminist Epistemologies, London, Routledge, 1993.

HERMIDA, M. "Colonialismo y producción de ausencias. Una crítica desde el Trabajo Social para visibilizar los presentes subalternos”, en Revista Debate Público. Reflexión de Trabajo Social, N²10, Buenos Aires, noviembre de 2015; pp. 66-85

HIRATA, H. y KeRGOAT, D. La división sexual del trabajo. Permanencia y cambio. Buenos Aires, Asociación Trabajo y Sociedad, 1987.

LAGARDE, M. Los cautiverios de las mujeres: madresposas, monjas, putas, presas y locas. México, Siglo XXI, 2005.

LUPORI, O. Oralidad y manuscritos varios. Cortesía del autor, 1999-2015.

MAFFIA, D. La subversión semiótica de la ciencia. Mimeo, 2001.

MORANDI, M. "Propuesta de trabajo presentada para el concurso de Ayudante de Primera para la Cátedra Taller de Aprendizaje Integrado IV”. Rosario, 2013. Cortesía de la autora.

NAJNAMOVICH, D. "El cuerpo del conocimiento, el conocimiento del cuerpo", en Cuadernos de Campo 7. Buenos Aires, 2009; pp. 6-13.

QUIJANO, A. “Colonialidad del poder, eurocentrismo y América Latina”, en Ladner, E. La colonialidad del saber: eurocentrismo y ciencias sociales. Perspectivas latinoamericanas. Buenos Aires, CICCUS/CLACSO, 2011. Pp. 219-264.

ROLNIK, S. Entrevista Cartografía sentimental, 1994. Disponible en: https:// es.scribd.com/document/36798629/Cartografia-sentimental-Suely-Rolnik

RUBIO, R. "De prácticas, afectos y saberes en la formación profesional del Trabajo Social. El rol de la supervisión académica”. En Revista Cátedra Paralela, N 13. UNR. Rosario, 2016. Pp. 77-104.

RUBIN, G. "The traffic in Women: Notes on the "Political Economy" of sex, en Rayna Reiter (comp.), Toward an Antropology of Women, Nueva York: Monthly Review Press, 1975.

SEGATO, R. "Territorio, soberanía y crímenes de segundo estado: la escritura en el cuerpo de las mujeres asesinadas en Ciudad Juárez", en Série Antropología, Brasilia, 2004.

SOSA, R. "Nuevas cartografías abiertas por las epistemologías feministas. Conocimientos situados, cronotopías culturales y movimientos en torno al saber y al poder en la teoría social latinoamericana". Trabajo presentado para el Posdoctorado del Centro de Estudios Avanzados, Universidad Nacional de Córdoba, 2017.

SOSA, R. Investigación-Acción-Participativa acerca de los dispositivos de entrenamiento para el cuidado de trabajadoras y trabajadores que intervienen en el campo de "lo social". Proyecto de Investigación y Desarrollo, UNR, 2018. 
El Trabajo Social interrogado por las epistemologías feministas. Cronotopías culturales y movimientos en torno al saber y al poder en la teoría social y en el trabajo social contemporáneo.

SASSEN, S. Contrageografías de la globalización. Género y ciudadanía en los circuitos transfronterizos. Madrid, Ed. Traficantes de sueños, 2003.

Recepción: 21/04/2018

Aceptación: 18/08/2018 